understanding has led to widely different views within it. Jewell suggests that doctors should inform the debate but not be involved in fundamental decision making, and this then raises the issue of who will, in fact, take on this responsibility. Jewell's suggestion that 'the public' will do so is disingenuous, given the obvious lack of unanimity of opinion within it. In any case, it seems curious to me for doctors to be urged to take such a passive role, when it is they who will be charged, quite literally, with the responsibility of delivering assisted suicide if it is introduced.

The risk here is that the voices of the politically powerful and influential will prevail. If they really want to safeguard the interests of their more vulnerable patients, doctors would do well to remember that there is a world of difference between being a public servant and a slave to majority public opinion.

\section{Roger Tisi,}

Audley Mills Surgery, Rayleigh, Essex, SS6 7JF. E-mail: rbtisi@googlemail.com

\section{REFERENCE}

1. Jewell D. Our debt to those who are dying Br J Gen Pract 2009; 59(568): 809-810.

DOI: 10.3399/bjgp09X473196

\section{Editor's comment}

Dr Alberti raises an important question, about the role of editors in setting the policy for journals. Mostly I have restrained myself from commenting: in 10 years this was, I think, only the third editorial I have published (there was a fourth that a trusted colleague persuaded me not to publish). But influence is exerted by the decisions on what to publish, which editorials are commissioned, and who is invited to write them. On this occasion I invited someone else, but when he declined I realised that I knew what content I wanted so decided not to hide behind someone else but to sign it myself $-E d$

\section{Obesity guidance}

\section{Mercer's discussion paper ${ }^{1}$ on the}

usefulness of clinical guidelines for the management of obesity in general practice is commendable and yet raises serious concerns.

It is misleading that the NICE obesity guidelines focus so much attention on drugs and bariatric surgery, neglecting the only true treatment (and prevention) options of lifestyle modification through increased physical activity and improved diet. In the summary NICE clinical guideline 43 , these get a single feeble line and this is a grossly misleading representation. One might also wonder how well equipped GPs currently are to, 'offering multi-component interventions to increase physical activity, increase healthy eating, and improve eating behaviour' during the average 9-minute consultation and when many GPs are not aware of the importance of physical activity. $^{2}$

This persistent focus away from physical activity and diet as the main primary and secondary prevention options are a worry and reflect educational needs and faults within modern medicine, where the true causes of chronic disease are neglected and forgotten, to an extent, to have been largely self-inflicted. Perhaps this is commercially driven by the pharmaceutical industry and the relative simplicity of researching drugs by RCTs with dichotomous outcomes (it works or it doesn't) against more complex long-term studies assessing physical activity and diet with numerous multi-end point outcomes. There are not much promising long-term data for obesity treatment with drugs, plenty of side effects, and none of the collateral benefits of regular physical activity, including the potential to treat and prevent over a dozen chronic conditions. ${ }^{3}$

NICE guideline 43 is also unjustified in promoting negative attitudes towards lifestyle improvements in primary care when these have not been researched. Evidence shows that even brief consultations (3-10 minutes) or simple pedometer-based programmes delivered through health professionals can lead to substantial increases in patients' activity levels (by approximately $30 \%$ ).

There is a lot of convincing evidence from exercise medicine alone to suggest that physical inactivity is the causal factor for most western chronic diseases (including obesity) rather than obesity per se. ${ }^{5}$ So, is it time to focus our resources on finding the best ways to achieve and sustain increased levels of physical activity and improvements in diet within primary care, rather than focusing on the unproductive symptom of obesity and increasing its societal stigma?

\section{Richard Weiler,}

Locum GP, Hertfordshire and Specialist Registrar in Sport \& Exercise Medicine, London Deanery.

E-mail: Richard.Weiler@uclmail.net

\section{Emmanuel Stamatakis,}

Senior Research Associate, National Institute for Health Research Post-Doctoral Fellow, University College London, Department of Epidemiology and Public Health.

\section{REFERENCES}

1. Mercer S. How useful are clinical guidelines for the management of obesity in general practice? $\mathrm{Br} J \mathrm{Gen}$ Pract 2009; 59(568): 863-868.

2. Gupta K and Fan L. Doctors: fighting fit or couch potatoes? Br J Sports Med 2009; 43(2): 153-154.

3. Kujala UM. Evidence on the effects of exercise therapy in the treatment of chronic disease. Br I Sports Med 2009; 43(8): 550-555.

4. Marcus BH, Williams DM, Dubbert PM, et al. Physical activity intervention studies: what we know and what we need to know: a scientific statement from the American Heart Association Council on nutrition, Physical Activity, and Metabolism (Subcommittee on Physical Activity); Council on Cardiovascular Disease in the Young; and the Interdisciplinary Working Group on Quality of Care and Outcomes Research. Circulation 2006; 114(24): 2739-2752.

5. Blair SN. Physical inactivity: the biggest public health problem of the 21st century. Br J Sports Med 2009; 43(1): $1-2$.

DOI: 10.3399/bjgp09X473204

\section{Familial hypercholesterolaemia}

Humphries et al report that a practice of 10000 patients is likely to have around 20 patients with familial hypercholesterolaemia who are at risk of premature coronary heart disease. ${ }^{1}$ They emphasise the importance of primary care in supporting adherence to lipid lowering treatment and lifestyle advice including exercise. Exercise is highly topical in view of the 2012 London Olympics and two recent UK government initiatives 'Be 
active, Be healthy' and 'Change4life'. ${ }^{2}$ For a medical student research project we examined self-reported exercise in cardiovascular and orthopaedic patients at Bedford Hospital. Following ethical review, Manning conducted a questionnaire survey in July 2009.

The response rate was $84 \%(63 / 75)$. Mean age of responders was 71 years (range 27 to 97 ) and 90\% were white. Although $86 \%$ reported exercising regularly, only $29 \%$ complied with $\mathrm{DOH}$ recommendations (30 minutes of moderate exercise five times a week). ${ }^{3}$ White patients were significantly more likely than those from ethnic minorities to participate in regular exercise (91\% 51/56 versus $43 \% 4 / 7, P<0.05)$. Similarly more men than women reported doing the $\mathrm{DOH}$ recommended amount of exercise $(50 \%$ 12/24 men versus 15\% 6/39 women $P<0.05)$. Comparable results have been seen in previous studies. ${ }^{4,5}$

Lack of awareness is a major problem in both exercise promotion and familial hypercholesterolaemia. Only one patient in our study knew how much exercise the $\mathrm{DOH}$ recommends. Similarly, it is estimated that $85 \%$ of people with familial hypercholesterolaemia remain undiagnosed. ${ }^{1}$ GPs are often the first point of contact for patients with chronic diseases such as familial hypercholesterolaemia. They may have a vital role both in diagnosis of this important condition and in exercise promotion.

\section{Serena Manning,}

4th year medical student.

\section{Pippa Oakeshott,}

Reader in General Practice, St George's, University of London, Cranmer Terrace, London, SW17 ORE.

E-mail: m0603345@sgul.ac.uk

\section{REFERENCES}

1. Humphries SE, Qureshi N, Minhas R, et al. Identification and management of familial hypercholesterolaemia: what does it mean to primary care? Br J Gen Pract 2009; 59(567): 773-777.

2. Department of Health. Be active, be healthy: a plan for getting the nation moving. London: $\mathrm{DoH}, 2009$.

3. Department of Health. At least five a week. London: DoH, 2004.

4. Department of Health. Health survey for England 2006 London: The Information Centre, 2008.

5. The Department of Health and Human Services. U.S. national physical activity statistics. Atlanta, GA: Centers for Disease Control and Prevention, 2007.

DOI: 10.3399/bjgp09X473213

\section{Respiratory infections}

I read the themed October BJGP on respiratory infections with both interest and nostalgia. I would like to make two general points.

First, although Verheij's admirable leading article uses and quotes the phrase 'antibiotic revolution', ', what struck me most in the linked papers was not how much has changed over the last 30 years, but how little things have changed. Wang et al's findings of large inter-practice prescribing variations ${ }^{2}$ closely mirror the pattern of the 1970s. And extrapolating from the data Meropol et a ${ }^{\beta}$ present, it seems that in 2004 just over $50 \%$ of all consultations for respiratory infections (combining his figures for adults and children) resulted in an antibiotic being prescribed, a figure not very different from the $58 \%$ we reported three decades ago. If there has been a drop in the volume of antibiotic prescribing, it is as likely to be due to changing demography or consultation availability, as it is to any sustained influence of educational interventions aimed at doctors.

Second, I was struck by the fact that none of the 121 references in the four relevant articles was to papers published earlier than 1990. This is part of a now regular pattern resulting from the increased use of review articles to introduce literature reviews and meta-analyses to summarise clinical trials. Although labour-saving for the author, this trend results in the airbrushing out of apposite historical work which might illuminate the work being undertaken.

In this case, I was obviously disappointed that none of the work I and others had been associated with in earlier years to try to describe and influence the determinants of antibiotic prescribing had earned a reference, not least because it contributes to understanding why unnecessary prescribing continues.
However, a solution is at hand. The $J$ Health Serv Res Policy runs a series 'Worth a Second Look', and I was recently invited to re-visit one of my apparently out-dated articles (from J R Coll Gen Pract 1972 entitled 'Diagnosis - the Achilles Heel'), and comment on its relevance to medicine today. The resulting paper is now available online ${ }^{4}$ and will be available in hard copy early in 2010. For those thinking of researching in this rich field, the essay includes relevant starter references, and also a model suggesting how difficult it is likely to be to make changes to the antibiotic prescribing status quo.

Come to think of it, given the proven effectiveness of the QOF financial incentives in changing patterns of care, ${ }^{5}$ why not simply debit practice incomes with the cost of all antibiotics prescribed, less whatever is deemed the necessary annual mean antibiotic requirement per patient? It could work

John Howie,

4 Raverig Park, Balerno, Edinburgh, EH14 7DL.

E-mail: john.howie00@btinternet.com

\section{REFERENCES}

1. Verheij TJM. The antibiotic revolution should be more focused. Br J Gen Pract 2009; 59(567): 716-717.

2. Wang KY, Seed P, Schofield P, et al. Which practices are high antibiotic prescribers? A cross-sectional analysis. Br J Gen Pract 2009; 59(567): e315-e20

3. Meropol SP, Chen Z, Metlay JP. Reduced antibiotic prescribing for acute respiratory infections in adults and children. Br J Gen Pract 2009; 59(567): e321-328.

4. Howie J. Diagnosis in general practice and its implications for quality of care. J Health Serv Res Policy 2009 [Epub ahead of print].

5. Campbell SM, Reeves D, Kontopantelis E, et al. Effect of pay for performance on the quality of primary care in England. N Engl J Med 2009; 361(4): 34-44.

DOI: 10.3399/bjgp09X473222

\section{Antidepressant prescribing}

In light of the debate concerning political targets to reduce antidepressant prescribing in Scotland, ${ }^{1}$ we were interested to see Cameron et al's paper addressing the appropriateness of antidepressant prescribing by GPs. ${ }^{2}$ After consulting our Aberdeen colleagues, we 